\title{
Epidemiology of road traffic accidents in Rafsanjan city, Iran
}

\author{
Leila Taravatmanesh ${ }^{1}$, Seyyed Mohsen Mortazavi ${ }^{2}$, Mohammad Reza Baneshi ${ }^{3}$, Mojtaba Shirbeygi Poor ${ }^{4}$, Arezoo
} Saeedifar ${ }^{5}$, Farzaneh Zolala ${ }^{6}$

\begin{abstract}
${ }^{1}$ M.Sc. of Epidemiology, Department of Biostatistics and Epidemiology, School of Health, Kerman University of Medical Sciences, Kerman, Iran

${ }^{2} \mathrm{MD}$, Head of Disaster Management and Emergency Response in Rafsanjan City, Rafsanjan University of Medical Science, Rafsanjan, Iran

${ }^{3}$ Ph.D. of Biostatistic, Social Determinants of Health Research Center, Institute for Futures Studies in Health, Kerman University of Medical Sciences, Kerman, Iran

${ }^{4} \mathrm{MD}$, Head of the Regional Center for Disaster Management and Emergency Response in Rafsanjan, Rafsanjan University of Medical Science, Rafsanjan, Iran

${ }^{5}$ M.Sc. of Epidemiology, Department of Biostatistics and Epidemiology, School of Health, Kerman University of Medical Sciences, Kerman, Iran

${ }^{6} \mathrm{Ph} . \mathrm{D}$. of Epidemiology, Social Determinants of Health Research Center, Institute for Futures Studies in Health, Kerman University of Medical Sciences, Kerman, Iran
\end{abstract}

\section{Type of article: Original}

\begin{abstract}
Introduction: Injury is recognized as a major health problem in most high and low-income countries. Rafsanjan is considered as one of the accident-prone areas in Kerman province.

Objective: To study the epidemiology of traffic accidents in the Rafsanjan city.

Methods: This cross-sectional study was conducted, by using the data from the Emergency Department (ED) of Aliebn Abitaleb Hospital in Rafsanjan city. The population included all people who had had a traffic accident in the city of Rafsanjan from March 21, 2014 through February 18, 2015. The sample included those who had been injured and transferred to the ED of Aliebn Abitaleb Hospital. Data were analyzed using Chi-square, independent-samples t-test, and logistic regression. SPSS software version 19 was used for data analysis. $\mathrm{P}<0.05$ was considered statistically significant.

Results: Age, gender and location of accident, had significant association with the number of mortalities $(p=0.02)$, and other results of this study suggest that there was a significant relationship between the status of the injured and the gender $(p<0.001)$, the accident location $(p<0.001)$, and the type of injury $(p<0.001)$.

Conclusion: The rate of accidents in one year in Rafsanjan city was high. Moreover, young people and motorcyclists had most accidents. Teaching the laws and regulations to the people of the city, is the most effective method in reducing accidents and mortality.
\end{abstract}

Keywords: Epidemiology, Traffic accident, Rafsanjan

\section{Introduction}

Injury is recognized as a major health problem in most high-income and low-income countries. Deaths caused by road accidents are defined as the deaths that occur during an accident or during the following month (1). Road accidents have increased among the general population due to the increasing use of vehicles, lifestyle changes and increased hazardous behavior (2). So, traffic accidents can be considered as the most important cause of death and

\section{Corresponding author:}

Assistant Professor Dr. Farzaneh Zolala, Social Determinants of Health Research Center, Institute for Futures Studies in Health, Kerman University of Medical Sciences, Kerman, Iran.

Phone: +98-9134422415, Email: zolalafarzaneh@gmail.com

Received: November 19, 2016, Accepted: October 25, 2017, Published: May 2018

iThenticate screening: August 31, 2017, English editing: December 26, 2017, Quality control: March 15, 2018

This article has been reviewed / commented by three experts

(C) 2018 The Authors. This is an open access article under the terms of the Creative Commons Attribution-NonCommercialNoDerivs License, which permits use and distribution in any medium, provided the original work is properly cited, the use is non-commercial and no modifications or adaptations are made. 
disability (2). Generally, about 1 to $3 \%$ of gross national income in developing countries is dedicated to the damage caused by road accidents. The World Health Organization reported that the mortality rate of road accidents in 1990 was about 9,900 and it reached 1.2 million in 2002 due to $10 \%$ growth (3). Results of the studies in Iran show that the death rate due to accidents is 30 per 100,000 people while it is 22.6 worldwide (3) and 15 out of 100 people who are injured in traffic accidents in Iran lose their lives, but this rate is about 2 in 100 in developed countries (3). According to the information from the statistics unit of the Legal Medicine Organization of Iran, 27,567 people were killed and 276,762 individuals were injured in traffic accidents in 2006. Furthermore, 23,000 people (4), in 2010, and 252,224 people with the rate of 34.1 in 100000 and $27.22 \%$ in 100000 in 2012 lost their lives in traffic accidents (1). Today, the deaths caused by traffic accidents have a critical situation in Iran. According to the head of the Traffic Police of Iran, every three minutes, a car accident occurs and every 19 minutes, one person is killed in a car accident (5). A study by Bos showed that $17.9 \%$ of all deaths caused by accidents in Europe had happened to motorcyclists (6). In a study by Ghorbani et al. in Gonbad-e Qavus city, it was indicated that in $62.7 \%$ of the accidents, the majority of vehicles were motorcycles and most of the injured people were motorcyclists (6) whose lower parts of their bodies were injured, especially with fractures to their legs (7). Results of a study by Khademi and Moradi showed that $73.4 \%$ of the victims of car accidents were men, and the main cause of death was head injury. Also, the majority of accident victims were passenger cars and then motorcycles (8). Rafsanjan city is located in the North West of Kerman province on the southern edge of the Lut Desert in communication routes of Kerman, Yazd, Fars, Hormozgan and Sistan-Baluchestan provinces and it is considered as one of the accident-prone areas in Kerman province. Upon reflection of the statistics by the Emergency Department in 2014, and due to the high build-up of traffic, we conducted this study to recognize the epidemiology of road traffic accidents and find ways to alleviate this problem.

\section{Material and Methods}

\subsection{Study design and sampling}

This is a cross-sectional study conducted on 4,899 subjects in the Rafsanjan population. Aliebn Abitaleb, is a large publicly funded hospital, in Rafsanjan. The Emergency Department (ED) personnel, register and document the cause of injury in the medical records for all cases that are admitted and treated for injury routinely on a 24-hour basis, based on the ninth Revision of WHO International Classification of Diseases, Clinical Modification (ICD-9-CM).

\subsection{Selection of cases}

The population included all people who had had traffic accidents in the city of Rafsanjan from March 21, 2014 through February 18, 2015. The sample included those who had been injured in that year and had been transferred to the ED of Rafsanjan Hospital. A retrospective on-site medical record review of injury-related ED visits from March 21, 2014 through February 18, 2015 was reviewed.

\subsection{Data collection}

Data for cases that accrued in the study period above were extracted from medical records of the ED onto a designed data collection form, this form is completed for each injured individual by an Emergency Technician, and variables include: age, sex, type of vehicles, the condition of the injured, type of injury, the temporal and spatial features of the injured, and deaths during the incidents. To define the variables included in the study, it should be noted that light vehicles refers to personal cars, heavy vehicles includes trucks, etc. and other vehicles refers to tractors and bulldozers. A data collection manual was prepared by the authors, who specified the aims of the study.

\subsection{Data Analysis}

We performed separate analyses for patients treated solely at the ED and those admitted. We used frequency, mean and standard deviation to describe the data. Chi-square and Independent-samples t-test were computed to compare proportions. Statistical Package for Social Sciences (SPSS) software version 19 was used for data analysis. $\mathrm{P}<0.05$ was considered statistically significant. The denominator for the calculation of the rate of accidents in 2014 was estimated based on the population in 2014 and the population growth rate (1.2\%) reported by the Statistical Center of Iran.

\subsection{Ethics of research}

The Ethics Committee of Kerman University of Medical Sciences approved the study protocol (date, 2015-06-29; ID, 10/8/1/27). We kept the information of the participants confidential. This study received ethical approval of the Aliebn Abitaleb Hospital Ethical Review Board, and the hospital administration allowed access to the medical records. 


\section{Results}

A total of 4,899 road accidents occurred in the city of Rafsanjan from March 21, 2014 through February 18, 2015 of which 39 cases $(0.8 \%)$ led to death. Regarding sex, 3,997 victims were men $(81.5 \%)$, and 898 were women $(18.3 \%)$ and 4 of them $(0.2 \%)$ had unidentified sex that had not been recorded. The mean age was $28.09 \pm 15.81$ years. The highest frequency of accidents occurred in the age group 20-30 years of age, of which there were 1,519 cases (31\%) and the least frequency was seen in people older-than 80 years of age. The results showed that in terms of the victims' status, 2,726 cases $(56.2 \%)$ were drivers, 1,313 cases $(33.1 \%)$ were passengers, and $511(10.5 \%)$ were pedestrians. Regarding the time pattern, the highest frequencies were observed in the summer (1,346 cases, 27.5\%) and in October (508 cases, 10.4\%) and the lowest frequencies were seen in the winter $(1,083$ cases, 22.2\%) and December (303 cases, $6.2 \%$ ), respectively. In terms of the types of injuries, the highest number of multi-injury cases was $1,652(33.8 \%)$ (injuries that occurred to several parts of the body), and after that, the injuries to the legs were 1,125 cases $(23 \%)$ and other injuries were 638 cases (13\%), respectively. In the studies on the types of injuries leading to death as well as those not leading to death, the frequencies of multi-injury cases were $39.9 \%$ and $33.8 \%$, respectively (Table 1). Result showed the types of injuries in the individuals who participated in the study. Regarding the traffic accidents that occurred in the city of Rafsanjan, motorcycles (56.3\%), light vehicles (37.8\%), heavy vehicles $(3.7 \%)$, bicycles $(1.6 \%)$ and other vehicles $(1.6 \%)$ had the largest share, respectively. It should be noted that in $0.4 \%$ of cases the type of vehicle involved in the accident was unknown. Among the people who had died in the accidents, the most frequent vehicles involved were light vehicles $(69.2 \%)$ and among the people who had survived the accidents, the most frequent vehicles were motorcycles $(56.5 \%)$. Classification of the accidents occurred in the city of Rafsanjan showed that $74.4 \%$ of fatal accidents had occurred outside the city and $25.6 \%$ had occurred inside the city while $60.9 \%$ of non-fatal accidents had happened inside the city and $39.1 \%$ of them had occurred outside. Results of the logistics regression analysis test showed that among the three variables age, gender and location of the accident (inside or outside the city), location of the accident $(\mathrm{p}=0.02)$ was significantly associated with the number of deaths and these results can be seen in Table 1. Other results of this study suggest that there is a significant relationship between the status of the injured and gender $(\mathrm{p}<0.001)$, the accident location $(\mathrm{p}<0.001)$, and the type of injury $(\mathrm{p}<0.001)$.

Table 1. Relationship between the three variables of age, gender and location, and death of the victims of traffic accidents

\begin{tabular}{|l|l|l|l|}
\hline Variable & Odds ratio (OR) & Confidence interval $(95 \% \mathrm{CI})$ & $\mathrm{p}$-value \\
\hline Age & 1.01 & $0.99-1.03$ & 0.2 \\
\hline Gender & 1.37 & $0.81-2.3$ & 0.2 \\
\hline Location & 2.2 & $1.09-4.4$ & 0.02 \\
\hline
\end{tabular}

\section{Discussion}

An accident might occur to a moving motor vehicle solely or between one or more other motor vehicles or pedestrians, animals or objects. This study examined the epidemiology of traffic accidents in the city of Rafsanjan from March 21, 2014 through February 18, 2015 and the findings showed that the accidents which occurred in that city did not have a high mortality rate, however, the number of accidents had been high. Based on the severity of the injuries in accidents, some people had been taken to hospital and others had not been referred to hospital. In general, most victims of road accidents were young people and men and the majority of the accidents had occurred in the summer and in October while the least accidents had occurred in the winter and in December. The remarkable point is that most accidents had occurred involving individuals driving light vehicles and then motorcycle riders. Findings of this study showed that the age group of 20-30 years old had had the highest number of accidents and this was consistent with the results of previous studies conducted by Mahahan in northern India, a study by Ali et al. in Kuwait, a study by Charkazi et al., and the one carried out by Charati et al. in Mazandaran province (4, 9-11). Most accidents occurred in this age group due to traffic, violations and use of illegal drugs. Also, they usually have little confidence in their own driving ability, do not fasten safety belts, and do not pay attention to the risks they personally induce. Moreover, driving inexperience is more prevalent among young people. Findings of this study indicated that, more than half of the victims were men and the ratio of traffic accidents by men to women was 4 to 1 . This finding was consistent with previous study conducted in Iran $(12,13)$. In a study conducted by Entezami et al. in the north of Iran more accident happened in young people, which is consist with our findings (12). One reason for the higher incidence in men compared with women is that men often drive at greater speed, agilely and tortuously, and use any unoccupied space and also continually change lanes (13). Furthermore, men are less likely to use safety belts. In contrast, women drive slowly and straightly. Caution and patience are some characteristics of women while driving. Findings of this study showed, most accidents had occurred in the summer and this was similar to the results of a study by Charkazi et al. (4). Summer vacation is a period of the year that most accidents happen due to the 
increasing volume of journeys and traveling. Findings of this study indicated that, regarding the type of injuries, most subjects had multi-injuries, and this was consistent with the study by Kumar et al. (10), but in a study by Shams Vahidi et al. (11), a study by Tanuch in India and other studies in Iran, heads were most likely to be injured (12-14). Findings of this study showed, in terms of the injured people's status, most victims were passenger-car drivers. This study is consistent with a study conducted by Sadeghi et al., and another study that had also come to the same conclusion in Shahrud city $(15,16)$. Regarding the type of vehicle, light vehicles and motorcycles had the highest number of accidents, respectively. However, in a study conducted by Mahajan in northern India, most accidents had occurred to light vehicles (17). A study carried out by Charkazi et al. in Golestan province concluded that the highest percentage of accidents had happened to motorcyclists (4). In our country, due to climatic, geographical, social and economic conditions, motorcycles have a significant contribution to transporting people. On the other hand, due to the lack of awareness and familiarity with regulations and possible risks, motorcyclists do not commit themselves to observe traffic laws and regulations as other vehicle drivers do. Consequently, they cause disasters leading to injuries and deaths. Findings of this study indicated, most accidents occurred during the day, this finding is consistent with a study conducted by Shadmani et al. (15), but is inconsistent with previous studies (18, 19). In the previous study conducted in Iran, by Bakhtiyari et al., the highest likelihood of accidents was during the evening (18). Moreover, in another study, Lam stated that most accidents had happened at night and that was not consistent with the results of our study (19). There is more traffic during the day. However, reasons such as the lack of developed roads and parking lots along with population growth and the increased number of vehicles that has led to heavier traffic should not be ignored. In addition, the rate of accidents in the evenings is higher than at sunset, because not only is the traffic heavier in the evenings, but also, drivers are tired and drowsy. Findings of this study showed that most accidents had happened inside the city and this was consistent with the study by Khosravi Shadmani (15). The findings obtained from logistic regression showed that the likelihood of death increased by increase of age. Compared to women, the risk of death in men is higher, and this finding is consistent with the study conducted by Khosravi Shadmani (15). Khosravi Shadmani, in his study, indicated that the risk of accident is lower on the roads outside the city than on the roads inside (15). Similarly, if an accident occurs outside the city, the likelihood of mortality will be $1.2 \%$ more than inside the city. Finally, as a result, it seems necessary to train and give knowledge to the personnel of the Emergency Department of Aliebn Abitaleb so that they could prevent the likelihood of death in people who suffer from traffic accidents by reacting quickly and timely. It should be noted that inappropriate actions of the relatives or the people who arrive at the scene before the first aid team may also increase the risk of death and this must be taken into consideration.

\section{Strengths and limitations}

The current study, which is one of few qualitative studies in Iran, was conducted in an Iranian context; however, its findings may be applied to other areas with a similar context. The limitation of this study was that this study was a cross-sectional study with a small sample; therefore, results could not be generalized to other populations in the world. Longitudinal studies are recommended to confirm these results.

\section{Conclusions}

In conclusion, findings of the study of traffic accidents over a one-year period in Rafsanjan city, showed the rate of accidents that had occurred was mostly high, but fortunately, the rate of mortality was low. Younger people as well as men had most accidents. However, since various studies carried out in Iran remind us that our younger age groups have the highest share of traffic accidents, and given the importance of this age group in Iranian society, conducting more studies with a wide range of the reasons for traffic accidents among the younger age groups as well as the associated causes of accidents along with interviewing Iranian youths, seems necessary to determine the reasons for the high rate of accidents in this group. We would like to thank the Aliebn Abitaleb hospital in Rafsanjan city and Kerman University of Medical Science for their generous financial support. We would also like to thank the participants who took part in this study.

\section{Acknowledgments:}

We would like to thank the Aliebn Abitaleb hospital in Rafsanjan city and Kerman University of Medical Science for their generous financial support. We would also like to thank the participants who took part in this study.

\section{Conflict of Interest:}

There is no conflict of interest to be declared. 


\section{Authors' contributions:}

All authors contributed to this project and article equally. All authors read and approved the final manuscript.

\section{References:}

1) Taravatmanesh S, Hashemi-Nazari SS, Ghadirzadeh MR, Taravatmanesh L. Epidemiology of fatal traffic injuries in the Sistan and Baluchistan province in 2011. Journal of Safety Promotion and Injury Prevention. $2015 ; 3(3): 60-5$.

2) Spoerria A, Eggera M, Elma EV. Mortality from road traffic accidents in Switzerland: longitudinal and spatial analyses. Accid Anal Prev. 2011; 43(1): 40-8. doi: 10.1016/j.aap.2010.06.009. PMID: 21094295.

3) Izadi N, Najafi F, Khosravi A, Hashemi SS, Salari A, Soori H. Estimation of mortality and calculated years of lost life from road traffic injuries. J Mazand Univ Med Sci. 2014; 24(112): 51-8.

4) Charkazi A, Esmaeili A, Garkaz G, Qoreishi Z, Gerey S , Nazari S. Epidemiologic Survey of Road Traffic Accidents in Patients dmitted in Emergency Department of Alejalil Hospital in, Aq-Qala City, Golestan Province. Journal of Health and of health; 2012; 3(2): 42-9.

5) Ziyab AH, Akhtar S. Incidence and trend of road traffic injuries and related deaths in Kuwait: 2000-2009. Injury. 2012; 43(12): 2018-22. doi: 10.1016/j.injury.2011.09.023.

6) Yazdani Cherati J, Baseri E, Ghadami M. Mapping of Mortality Rate in Suburban Accidents, Mazandaran Province 2007-2010. Mazandaran Univ Med Sci. 2012; 22(97): 50-8.

7) Jankowiak, Janet. Assessing the older driver, Massachusetts Medical Society, 2006.

8) Entezami N, Hashemi-Nazari SS, Soori H, Khosravi A, Ghadirzadeh MR. Epidemiology of fatal road traffic accidents in Northern provinces of Iran during 2009 to 2010. Safety promotion and injury prevention. 2015; 3(1): 1-8.

9) Hannaa, CL, Laflammeb L. Bingham CR. Fatal crash involvement of unlicensed young drivers: County level differences according to material deprivation and urbanicity in the United States, Accident Analysis and Prevention. 2012; 45: 291-5. doi: 10.1016/j.aap.2011.07.014.

10) Kumar A, Lalwani S, Agrawal D, Rautji R, Dogra TD. Fatal road traffic accidents and their relationship with head injuries: An epidemiological survey of five years. Indian Journal of Neurotrauma. 2008; 5(2): 637. doi: 10.1016/S0973-0508(08)80002-0.

11) Shams Vahdati S, GhafarZad A, Rahmani F, Panahi F, Omrani Rad A. Patterns of Road Traffic Accidents in North West of Iran during 2013 New Year Holidays: Complications and Casualties. Bull Emerg Trauma. 2014; 2(2): 82-5. PMID: 27162871, PMCID: PMC4771298.

12) Kanchan T, Kulkarni V, Bakkannavar SM, Kumar N, Unnikrishnan B. Analysis of fatal road traffic accidents in a coastal township of South India. J Forensic Leg Med. 2012; 19(8): 448-51. doi: 10.1016/j.jflm.2012.02.031. PMID: 23084306.

13) Hashemi Nazari S, Kazemian M, Hosseini F. Trend Of Five Years Traffic Accident Mortality in Khuzestan Province ( 2006-2010). Scientific Journal of Forensic Medicine. 2011; 17( 2(62): 123-9.

14) Zadeh HS, Vahabi R, Nazparvar B, Amoei M. An epidemiological study and determination of causes of traffic accident-related deaths in Tehran, Iran during 2000-2001. Journal of clinical forensic medicine. 2002; 9(2): 74-7. doi: 10.1054/jcfm.2002.0547.

15) Khosravi Shadmani F, Soori H, Ainy E, Zayeri F, Mehmandar MR. Comparison of road traffic death occurrence within urban and metropolitan roads focusing on environmental factors. Hakim. 2013; 15: 339445.

16) Nantulya VM, Reich MR. The neglected epidemic: road traffic injuries in developing countries. BMJ. 2002; 324(7346): 1139. doi: 10.1136/bmj.324.7346.1139. PMID: 12003888, PMCID: PMC1 123095.

17) Mahajan N, Bhardwaj A, Gupta A, Kumar Raina S , Gupta BP. An epidemiological study on the road traffic accidents from hills of north India; Burns \& Trauma, Int J Crit Illn Inj Sci. 2013; 3(3): 190-4.

18) Bakhtiyari M, Soori H. Epidemiology of traffic crushes outcome and related factors in Iran 2010. Journal of safety promotion and injury prevention. 2013; 1(3): 150-9.

19) Lam LT. Environmental factors associated with crash-related mortality and injury among taxi drivers in New South Wales, Australia. Accid Anal Prev. 2004; 36(5): 905-8. doi: 10.1016/j.aap.2003.10.001. PMID: 15203368 . 